\title{
VIABILITY STUDY OF BIOFILM-FORMER STRAINS FROM PAPER INDUSTRY BY FLOW CYTOMETRY WITH APPLICATION TO KINETIC MODELS
}

E. Torres, M. Ladero, P. López, A. Alcon, V. Santos, A. Blanco.

Chemical Engineering Department. Faculty of Chemistry.

Complutense University of Madrid.

Madrid 28040. Spain.

\begin{abstract}
Biofouling causes important economic losses in the paper industry. To prevent or mitigate the effects of biofilms is necessary to implement microbiological control programmes based on monitoring programs which requires the evaluation of the biofilm growth kinetic taking into account the ability of microorganisms viability. The monitoring techniques must be rapid to minimise both costs and use of chemicals. This paper presents the study of the growth kinetics of two bacterial strains known for their high capacity to produce biofilms in paper mills. After the validation of flow cytometry as a technique for microbial growth monitoring, the development of segregated kinetic models based on cell physiological states data was carried out. The developed models can be used to design microbial control programs.
\end{abstract}

\section{Introduction}

The presence of biofilm-forming microorganisms in the water circuits of paper mills has become a critical issue nowadays due to the closure of the water circuits that increase both temperature and organic load in process waters, two aspects that favour microbial growth and biofilm formation (Johnsrud, 2000; Blanco, 2003; Blanco et al., 2004). 
Microorganisms present in biofilm can generate volatile compounds (e.g. organic acids, sulphur compounds and amine compounds) that cause nuisance odours as a result of their metabolism. Moreover, mature biofilms eventually detach from the surface that they cover causing disruptions in the production, frequently leading to unacceptable quality defects in the final paper (Blanco et al., 1996; Blanco, 2003; Lahtinen et al., 2006; Rättö et al., 2006).

Most studies in the paper industry have been focused on the effects of antimicrobial agents (biocides, enzymes and dispersing) on sessile and planktonic cells although in the last years the effort has been focused on the characterization of biofilm structure and microbial composition. These studies provide information on the importance of certain microorganism strains in the early stages of biofilm formation (Kolari et al., 2003) and on the amount and type of polysaccharides that they produce (Verhoef et al., 2005). Thus specific control programs can be developed e.g. by new enzymatic treatments (Torres et.al., 2008) being essential a good understanding of their growth.

Two cell processes are associated with the growth of microorganisms: uptake of material from the environment and the release of metabolic end products into the medium that can influence the physiological state, their proliferation, and the development of resistance mechanisms against increasingly hostile environments (Vives-Rego et al., 2000; Hewitt and Nebe Von Caron, 2004; Hammes et al., 2008). The death of a bacterial cell has long been defined as its inability to grow to a visible colony on bacteriological media. This assumption is simplistic and numerous situations have been described in which cells lose culturability but remain viable and are potentially able to grow. Knowing when 
the dynamics of the transitions and the interaction between cellular states take place is important when conceiving control strategies to avoid biofilm formation. The most common techniques used to monitor the proliferation of microorganisms in industrial control programmes such as dry cell weight, culture medium turbidity (optical density), plating method or ATP measurements, fail to provide information on aspects such as cell viability or resistance, because they observe the bacterial death only in retrospective (Berney et al., 2006). Actually there are clear evidences of the presence of intermediate cell states which remained undetectable by classical methods in both natural industrial samples and laboratory axenic cultures (Diaz et al., 2010).

The application of flow cytometry (FC) together with viability indicators based on fluorescent molecules, is a technique for cultivation-free analysis of bacterial viability in disinfection experiments, food biotechnology, industrial biotechnology and environmental samples (Alcon et al., 2004; Berney et al., 2006; Lacroix and Yildrin, 2007; Foladori et al., 2010). This technique provides quantitative information on the different physiological states of the cells in a fast and reliable way enabling to obtain real-time data that can be used in the development of more accurate control programmes (Hewitt and Nebe-von-Caron, 2004; Herrero et al., 2006; Labas et al., 2008; Torres et al., 2008). Each indicator is based on criteria that reflect different levels of cellular integrity or functionality.

Quantitative information on cell state dynamics obtained from flow cytometry analysis may allow researches to propose and to verify mathematical models to describe the kinetic behaviour of the subpopulations measured. These kinetic models describe the temporal evolution of the concentration of microorganisms 
in a system, as a function of relevant intrinsic or extrinsic variables based on different stages of viability (Herrero et al., 2006; Marks, 2008; Quiros et al., 2007; Quiros et al., 2009).

The main objective of this paper is to develop a methodology to study the physiological state of biofilm-forming bacteria from paper mills, through flow cytometry analysis of bacterial subpopulations during growth, and to develop and validate predictive kinetic models that will be use in the future to optimize the industrial biofilm control programs.

\section{Materials and Methods}

\section{Isolation of bacterial species}

The bacterial species Brevundimona vesicularis VTT E-981024 and Bacillus simplex E-022115 were isolated from slime samples obtained from two paper mills. One is located in Finland and the other in Spain. These strains were selected because their high capability of producing EPS (Verhoef et al., 2005)

\section{Experimental set-up}

Pre-inocula were prepared using shake flasks at $37^{\circ} \mathrm{C}$ and $150 \mathrm{rpm}$ in a medium containing glucose $\left(20 \mathrm{~g} \cdot \mathrm{L}^{-1}\right)$, yeast extract $\left(0.5 \mathrm{~g} \cdot \mathrm{L}^{-1}\right),\left(\mathrm{NH}_{4}\right)_{2} \mathrm{SO}_{4}(0.6$ $\left.\mathrm{g} \cdot \mathrm{L}^{-1}\right), \mathrm{KH}_{2} \mathrm{PO}_{4}\left(3.18 \mathrm{~g} \cdot \mathrm{L}^{-1}\right), \mathrm{K}_{2} \mathrm{HPO}_{4}\left(5.2 \mathrm{~g} \cdot \mathrm{L}^{-1}\right), \mathrm{MgSO}_{4} \times 7 \mathrm{H}_{2} \mathrm{O}\left(0.3 \mathrm{~g} \cdot \mathrm{L}^{-1}\right)$, $\mathrm{CaCl}_{2}\left(0.05 \mathrm{~g} \cdot \mathrm{L}^{-1}\right), \mathrm{ZnSO}_{4} \times 7 \mathrm{H}_{2} \mathrm{O}\left(0.2 \mathrm{mg} \cdot \mathrm{L}^{-1}\right), \mathrm{CuSO}_{4} \times 5 \mathrm{H}_{2} \mathrm{O}\left(0.2 \mathrm{mg} \cdot \mathrm{L}^{-1}\right)$, $\mathrm{MnSO}_{4} \times \mathrm{H}_{2} \mathrm{O}\left(0.2 \mathrm{mg} \cdot \mathrm{L}^{-1}\right), \mathrm{FeSO}_{4} \times 7 \mathrm{H}_{2} \mathrm{O}\left(0.6 \mathrm{mg} \cdot \mathrm{L}^{-1}\right)$ and $\mathrm{CoCl}_{2}\left(0.2 \mathrm{mg} \cdot \mathrm{L}^{-1}\right)$. The volume of inoculum required to obtain an initial biomass concentration of $0.1 \mathrm{~g}^{\cdot-1}$ in the bioreactor was determined through calculations based on the measurement of the inoculum optical density (OD). 
Each bioreactor (Sartorius model Biostat B- plus of $1 \mathrm{~L}$ ) was seeded with the volume of inoculum calculated previously. The medium employed for cultivation was the same as the one used for inoculum preparation. The bioreactors were operated at $1 \mathrm{~L} \cdot \mathrm{min}^{-1}$ air flow rate, $150 \mathrm{rpm}$ stirrer speed and $37^{\circ} \mathrm{C}$; the medium $\mathrm{pH}$ was adjusted to 6.8-7.0. The evolution of bacterial subpopulations during the experiments was monitored by turbidity measurements and FC every hour until reaching the stationary phase of growth.

\section{Turbidity measurements}

Turbidity measurements were carried ot with a spectrophotometer (AQUAMATE model spectrophotometer; Thermo scientific) first for the elaboration of a turbidity calibration curve along with the preparation of a pre-inoculum, and second for the monitoring of bacterial cultivation in the bioreactor.

The evolution of the biomass was determined by measuring the OD600 (optical density at $600 \mathrm{~nm}$ ) of the medium during bacterial growth versus a blank (the same medium without cells). OD data were converted to dry weight using the corresponding calibration curve, and the results were finally expressed as $g \cdot L^{-1}$.

\section{Flow citometry}

FC measurements were carried out using a FAC Scalibur cytometer (Becton Dickinson, San Jose, CA, USA) equipped with an air-cooled $15 \mathrm{~mW}$ argon-ion laser emitting at a fixed wavelength of $488 \mathrm{~nm}$ and a viability kit provided by Becton Dickinson. Fluorescent filters and detectors were all standard, with green fluorescence collected in the FL1 channel $(530 \pm 30 \mathrm{~nm})$ and red fluorescence collected in the FL3 Channel $(>670 \mathrm{~nm})$. All parameters were 
collected as logarithmic signals. Data were analysed using the CellQuest ${ }^{\mathrm{TM}}$ software from Becton Dickinson.

\section{Total number of bacteria}

The evaluation of membrane integrity is the most definitive evidence of cell viability. Cells without an intact membrane cannot maintain or generate the electrochemical gradient which generates membrane potential, and can be classified as dead cell (Nebe-Von Caron et al., 2000). Their structures are exposed to the medium and finally decompose and lyses. Membrane integrity can be detected by dye exclusion or dye retention. Cells with intact membrane are permeable to multiple charged dyes such as SYTOX stains (Gregory et al., 2001; Quiros et al., 2009) or to cyanine's (TOPRO, TOTO series) and impermeable to dyes such as $\mathrm{PI}$, which only leaks into cells with compromised membranes. Therefore, to distinguish the different physiological states of cells, namely dead, non culturable and viable cells a kit including Liquid Counting Beads (LCB) and two fluorochromes as viability markers, Thiazole Orange (TO) and Propidium lodide $(\mathrm{PI})$ were used. TO is a permeable dye and enters all cells, live and dead, to vary degrees. PI was used as viability marker since it is a large, double-positively charged molecule that binds to DNA and RNA and does not penetrate cells with intact cytoplasmic membranes (Joux and Lebaron, 2000; Novo et al., 2000; Shapiro, 2003). Staining of cells with PI is therefore indicative of severe membrane damage and, as a result, $\mathrm{PI}$ is normally viewed as a conservative indicator of cell death (Lisle et al., 1999; Berney et al., 2006), although some exceptions have been noted (Novo et al., 2000; Shi et al., 2007). TO presents affinity for DNA, but also for cell membrane lipids, what enables it 
to penetrate cells having their membrane intact (Xiaofeng and Krull, 2005). With gram-negative organism, depletion of the lipopolysaccharide layer with EDTA greatly facilitates TO uptake. During this study, it was assumed that cells having intact membranes are marked only with OT, the damaged cells have a double labelling $(\mathrm{PI}+\mathrm{OT})$ and dead cells are marked only with PI. LCB were added to each sample as an internal reference, following the supplier's recommendations for ratiometric counting.

Samples were made to flow at low velocity and data were acquired in log mode taking about 10000 events, of which around 1000 corresponded to bead events. The beads added, having a known number, were used to assess the reliability of the FC measurements. Cellular concentration was expressed in $\mathrm{g} \cdot \mathrm{L}^{-1}$.

Each cellular suspension sample $(500 \mu \mathrm{L})$ was diluted with a phosphatebuffered saline solution (PBS with $0.1 \%$ Tween 80 ) to an approximate concentration between $10^{5}$ and $10^{6}$ cells $/ \mu \mathrm{L} .500 \mathrm{~mL}$ of these diluted samples were then stained with $\mathrm{TO}$ at $17 \mu \mathrm{M}$ of $\mathrm{TO}$ and left to incubate for 15 minutes at room temperature. Immediately after, PI at $1.9 \mathrm{mM} \mathrm{PI}$ and $50 \mu \mathrm{L}$ of a suspension of 981 beads per $\mu \mathrm{L}$ were added. Subsequently, samples were analysed by FC. Once the population considered in this study was delimited, an analysis of the fluorescence of each cell in the population was performed to quantify the cellular viability. This was carried out by plotting, for each cell, the fluorescence intensity of TO versus that of PI. The location of each point within the plot enabled to associate the cell to one of the three bacterial subpopulations (dead cells, non culturable cells and viable cells).

In the dot plots obtained for each sample a single bacterial strain was clearly detected (Figure 1), ruling out the possibility of sample contamination. A further 
analysis enabled us to quantify the percentages of living, non culturable and dead cells in each experiment. To determine the absolute cell count the equation 1 was used:

$\left(\begin{array}{c}\begin{array}{c}\text { No.events } \\ \text { containing cell population } \\ \text { No.events in bead } \\ \text { population }\end{array}\end{array}\right) \times\left(\begin{array}{c}\text { No.beads per test } \\ \text { Test volume } \\ \text { population }\end{array}\right) \times$ dilution factor $=\begin{gathered}\text { Concentration of bacterial } \\ \text { population }(\text { cells } / \mu L)\end{gathered}$

Model development

To study the dynamic relationship among the different kind of cells, two kinetic models considering the temporal evolution of all of them have been used, they consider the logistic equation to be fitted to viable and dead cell populations.

The fitting of the kinetic models to experimental data was performed using the Marquardt-Levenberg algorithm coupled with a modified Euler's method with variable step for the numerical integration of the kinetic equations (Denis et al., 1981; Gautschi, 1997). The selection of the most appropriate model was based on usual physical (positive value of the kinetic parameters) and statistical criteria (standard error value for each kinetic parameter, Fischer`s F95, Akaike's modified information criterion and sum of squares of weighted errors (SQR) values for each kinetic model). In this work, $F_{95}$ value is calculated by equation 2 , hence a high number of parameters involves a great reduction in its value:

$$
\mathrm{F}_{95}=\frac{\sum_{\mathrm{n}=1}^{\mathrm{N}}\left(\mathrm{y}_{\text {calc }}\right)^{2} / \mathrm{K}}{\sum_{\mathrm{n}=1}^{\mathrm{N}}\left(\mathrm{y}_{\text {exp tal }}-\mathrm{y}_{\text {calc }}\right)^{2} /(\mathrm{N}-\mathrm{K})} \therefore \mathrm{SQR}=\sum_{\mathrm{n}=1}^{\mathrm{N}}\left(\mathrm{y}_{\text {exp tal }}-\mathrm{y}_{\text {calc }}\right)^{2}
$$

Donde $Y_{\text {calc }}$ is the calculated value, $Y_{\text {expetal }}$ is the value obtained in the experimentation, $\mathrm{N}$ is the studied population and $\mathrm{K}$ is a random variable. The 
Akaike's information criterion also places a penalty on the use of excessive parameters in any model used to be fitted to experimental data. Information criteria were created in the first seventies and have continuously been developed, probed into and applied in a variety of fields in the last twenty years (Akaike, 1976; Knol et al., 2010). The original Akaike's information criterion (AIC) was devised for very large sets of data. When the ratio of number of data to number of parameters is lower than 40 , it is better to use a modified version of this information criterion, the AICc:

$$
\mathrm{AICc}=\operatorname{Ln}\left(\frac{\mathrm{SQR}}{\mathrm{N}}\right)+\frac{\mathrm{N}+\mathrm{K}}{\mathrm{N}-\mathrm{K}-2}
$$

Where $\mathrm{N}$ is the population studied, and $\mathrm{K}$ is a random variable. The higher the $\mathrm{F}$ and the lower the AICc parameter values, the more prone the model is to be correct from a statistical point of view.

\section{Results}

Turbidity (OD) versus FC (as g. $\left.L^{-1}\right)$

Total concentration analysis of bacteria growth at each sampling time was obtained through OD and FC measurements by triplicate (Figure 2). Each strain was monitored including the stationary phase.

Results obtained with the total biomass by OD and cellular counts by FC for 981024 and 22115 strains show a good correlation. The behaviour showed by the two strains was significantly different, and so was the final biomass concentration achieved. The 981024 strain seems not to require a large period of adaptation to the growing medium, starting its exponential growth phase in only one hour after introducing the inoculums (initial fermentation time). The exponential phase was maintained continuously and slowly during the following 
$15 \mathrm{~h}$ of culture without reaching the stationary phase. In the case of the 22115 strain the exponential phase takes $2 \mathrm{~h}$ to begin, being its evolution quicker than in the case of the 981024 strain. The 22115 strain reached the maximum concentration in 9h. When comparing the results of $\mathrm{FC}$ with the $\mathrm{OD}$ measurement for each organism, it is clear that biomass is a measure of the total concentration of cells. The OD and biomass concentration values achieved at the end of the experiments were $0.68(\mathrm{OD})$ and $0.77(\mathrm{FC}) \mathrm{g} \cdot \mathrm{L}^{-1}$ in the growth of the 981024 strain (15h) and $4.98(\mathrm{OD})$ and $5.16(\mathrm{FC}) \mathrm{g}_{\mathrm{L}} \mathrm{L}^{-1}$ in the case of the 22115 strain. In general, the growth trend for the two strains was similar for both techniques, but the bacterial concentrations $\left(\mathrm{g} \cdot \mathrm{L}^{-1}\right)$ determined by $\mathrm{FC}$ were slightly higher, similar to data obtained by Quiros et al. (2007) in their study on physiological states of microorganisms.

This concentration is obtained by measuring the turbidity of the broth so that both the viable and dead cells, contribute to the turbidity. By contrast, FC informs on the status of biomass formed during bacterial growth and therefore this technique provides much more information, as already mentioned. Turbidity measurements cannot differentiate subpopulations or discriminate microorganism of debris (Quiros et al., 2007) being these relevant data for controlling problematic microorganisms in industrial processes (Olivier, 2005). The behaviour of microorganisms is useful for the application of antimicrobiological control programs or for the improvement of bioprocesses (Quiros et al., 2007; Labas et al., 2008). The results show that using the FC technique along with fluorescents markers is possible to carry out cell differentiation far beyond cell viability. 
Physiological states by FC

Multiparametric FC measurements reveal the presence of intermediate physiological states between life and cell death, showing the inherent heterogeneities of microbial populations. The cells can be classified according to some active functions or the integrity of cell structures.

As can be seen in Figure 3, analysis results of the 981024 strain showed that, at zero time, the percentage of dead and damage cells were $17 \%$ and $14 \%$, respectively. Damaged cells increased their percentage in the first three hours up to $49 \%$, maintained by an interval time short, then this percentage decreased to 10 hours where it remained more or less at $20 \%$ with respect to the total biomass.

The percentage of dead cells increased right from the beginning of the experiment. From hour 4 until hour 10 this increase was more pronounced, becoming less steep in the subsequent hours and reaching the $35 \%$ of the total biomass at the end of the experiment. These final values of the percentage for the two populations were maintained until the 15 hours of growth.

On the other hand, the 22115 strain had a percentage of $18 \%$ and $10 \%$ at $0 \mathrm{~h}$ for both dead and damage correspondingly. Damage cells increased from hour two until hour three, reaching a percentage of $39 \%$, the sub-population then decreased exponentially until hour 6 , reaching values of $12 \%$ and remained constant until 10 hours. Dead cells initiated a population increased within 2 hours of cultivation, reaching $25 \%$ that remained constant until $10 \mathrm{~h}$ of cultivation.

FC monitoring allowed a rapid and accurate quantification of biomass at a given time during the experiments. The results obtained to assess the different 
degrees of membrane integrity can be associated to the presence of intermediate cellular states (Amor et al., 2002).

Kinetic model

The population dynamics of the two strains considered in this study were modelled based on a simplified reaction scheme with the following assumptions:

(1) the total biomass is constituted by three subpopulations.

(2) viable bacteria may become damaged bacteria, with damaged cell walls.

(3) during the first hours of growth, the main evolution observed is that of viable cells to damaged bacteria.

(4) after this period, viable cells reproduce mainly to other viable cells, while damaged cells are produce at a lower rate and evolve towards dead bacteria.

The following reaction scheme was based on afore mentioned assumptions:

Viable cells $\rightarrow$ Damaged cells $\quad($ step 1$)$

Damaged cells $\rightarrow$ Dead cells $\quad$ (step 2)

Viable cells $\rightarrow$ Viable cells $\quad$ (step 3 )

With all or some of these assumptions, two kinetic models were tested. Being growth models, these models permitting evaluate several cellular physiologic states considering the first three phases of the growth of microorganisms (they are segregated models), do not include substrate nor other metabolites kinetics (they are non structured models). The models are based on the logistic equation applied to both viable and dead cells, as their kinetic curves are similar in shape and damaged cell dynamics can be described from them. The difference between the two models emanates from the consideration of the existence of one or more stages considering the kinetic relationships among cell subpopulations. Time has been used as the variable where these changes in 
kinetic relationships are reflected. The first model considers that there is no change in the trend of viable cells during cell growth in evolving toward viable or towards damaged cells, so there is no change in kinetic relationships of the different subpopulations involved, and, thus, assumptions 3 and 4 are not applied. The second model reflects that viable cells are the source of damaged cells in the first hours of growth, while they yield mainly viable cells in a second stage. In this second stage, damaged cells evolve towards dead cells. This time discontinuity is introduced in the model through kinetic parameters or time constants that involve modifications of the independent variable, time.

In both models, the evolution of viable and dead cells is fitted by the respective logistic equation, given by:

$$
\begin{aligned}
& C_{V}=\frac{C_{V \max } \cdot C_{V 0} \cdot e^{k_{1} t}}{\left(C_{V \max }+C_{V 0} \cdot\left(e^{k_{1} t}-1\right)\right)} \\
& C_{M}=\frac{C_{M \max } \cdot C_{M 0} \cdot e^{k_{2} t}}{\left(C_{M \max }+C_{M 0} \cdot\left(e^{k_{2} t}-1\right)\right)}
\end{aligned}
$$

Where, $\mathrm{C}_{v_{\max }}$ is the maximum concentration of viable cells, $\mathrm{C}_{\mathrm{v} o}$ is the initial concentration of viable cells, $k_{1}$ is the constant speed of growth of viable cells, $t$ is time, $\mathrm{C}_{\mathrm{Mmax}}$ is the maximum concentration of dead cells, $\mathrm{C}_{\mathrm{M}}$ is initial concentration of dead cells and $\mathrm{k}_{2}$ is the constant maximum growth rate of dead cells.

Damaged cells are related to viable and dead cells. Damaged cell concentration generated from viable cells can be fitted by:

$$
C_{D 1}=k_{3} \cdot \frac{C_{v_{\max }} \cdot C_{v_{0}} \cdot e^{k_{1}\left(t-t_{v}\right)}}{\left(C_{v_{\text {max }}}+C_{v 0} \cdot\left(e^{k_{1}\left(t-t_{v}\right)}-1\right)\right)}
$$


Where, $\mathrm{k}_{3}$ is the constant of first order between viable cells and damaged $t v$ is and the time variation of damaged cells on the living.

At a given time, damaged cells begin to evolve towards dead cells. This kinetic phenomenon can be represented using this equation:

$$
C_{D 2}=k_{4} \cdot \frac{C_{M \max } \cdot C_{M 0} \cdot e^{k_{2}\left(t-t_{m}\right)}}{\left(C_{M \max }+C_{M 0} \cdot\left(e^{k_{2}\left(t-t_{m}\right)}-1\right)\right)}
$$

Where, $\mathrm{k}_{4}$ is the constant of first order between the damaged and dead cells and $t_{m}$ is the time variation of the damaged cells with respect to the dead.

Therefore, the temporal evolution of total damaged cells is given by the following cell mass balance:

$$
C_{D}=C_{D 0}+C_{D 1}-C_{D 2}
$$

Here, $t_{v}$ and $t_{m}$ are zero in model 1 , not being therefore considered, while they are non-zero for model 2, so several growth stages are possible in this latter model, reflecting assumptions 4 and 5 .

The results of the fitting are shown in Tables 1 and 2. Results showed that model 2 is the most adequate from a statistical point of view, with high values for $\mathrm{F}_{95}$ and low values for the AICc criterion. These good fittings of model 2 to kinetic data are evident in Figures 4 and 5, where the dynamics of the non culturable subpopulation are only well described by model 2 , with data from both strains.

The negative values of tm and tv mean that the population of damaged bacteria increases at lower time values than the population of viable and dead cells. This is evident in both Figures 4 and 5, where the growth rate at zero time for damaged bacteria is always the highest. The presence of a maximum at low time values suggest the adaptation of viable cells to growth medium and, from 
that time on, or even at a slightly lower time value, viable cells seems to create mainly other viable cells. This event is concomitant with the sharp decrease in the creation of bacteria with compromised cell walls. An hour or less before, and with both strains, damaged bacteria have started to evolve rapidly to dead cells, considering the values of $t_{v}$ and $t_{m}$.

Quiros et al. applied a non-structurated segregated growth model, where the substrate is used for the growth of viable bacteria and the maintenance of both viable and non culturable bacteria (Quiros et al., 2007; Quiros et al., 2009). One of the differences is that this model takes into account the role of the substrate, so first order and Monod kinetic equations are considered for the rate of evolution of all subpopulations. Therefore, no logistic equation is used. Other great difference is the consideration of two types of viable cells: those culturable and viable, and those viable but non culturable (VNBC). The evolution of viable and non culturable (VNBC) bacteria followed sigmoid trends with time (Quiros et al., 2007), or viable and culturable cells decrease with time or have a maximum at a certain growth time (Quiros et al., 2009). In these studies, dead cells showed no sigmoid trends with time, but a linear trend, and their population increased steadily with time. Moreover, the population of VNBC was really higher than that of viable and culturable cells, and never decreased, entering a plateau or stationary phase. At the same time, damaged cells population is always very low and, in some cases, increases a little with time, following the trend of dead cells but with almost negligible concentration values. In the case of this study (data not shown), evolution of substrate is directly linked to evolution of viable cells (including culturable and non culturable) during the first hours of growing, and almost no substrate seems to be used for the 
maintenance of cells with disrupted cell walls. The damaged cell population with both strains goes through a maximum to give a residual number at high fermentation times that, in the case of E-022115, is almost zero. This involves that cellular dynamics with these strains are different to those of Quiros et al., regarding especially the behaviour of the dead and damaged cell subpopulations.

Nevertheless, both kinetic models are based on the Ricatti model (the one by Quiros and co-workers) and a particular form of that model, the integrated logistic equation. The application of the model of Quiros et al. $(2007,2009)$ to our data (using total viable, damaged and dead subpopulations data) rendered poor results, neither allowing the fitting of damaged cells nor yielding kinetic parameters reasonable from the statistical viewpoint, with too wide error intervals, too low $F_{95}$ values, due to the scarce capacity of this model to fit experimental data of this study. Therefore, another approach was undertaken by integrating and modifying the logistic equation for viable and dead cells. The integration of the logistic equation has allowed for the inclusion of time constants for damaged bacteria ( $t_{v}$ and $t_{m}$ ), thus including time variances in growth among subpopulations and creating, by this strategy, three stages in the relationships among the different kinds of cells without taking into account the substrate evolution.

\section{Conclusions}

The developed methodology based on FC used with fluorescent markers allows us to determine the cell states far beyond cell viability. The quantitative information on cell state dynamics obtained from FC analysis allows us the 
proposal and verification of mathematical models describing the kinetic behaviour of the subpopulations measured.

Two segregated growth models for two biofilm forming microorganisms are proposed and calibrated with experimental data gathered for each strain. The first model considers that there is no change in the trend of viable cells during cell growth in evolving toward viable or towards damaged cells, so there is no change in kinetic relationships of the different subpopulations involved. The second model is more complex and reflects that viable cells are the source of damaged cells in the first hours of growth, while they yield mainly viable cells in a second stage. In this second stage, damaged cells evolve towards dead cells. For the both microorganisms studied, the most complicated kinetic model presents a good agreement with the experimental data (standard errors between 0.2 and $6 \%$, depending on the cell subpopulation and microorganism considered, while model 1 fits experimental data with standard errors ranging from 0.7 to $11 \%)$.

This type of models together with studies of biofilm control can be used to design chemical control protocols that maximize efficacy while minimizing the use of chemicals. 


\section{References}

Alcón, A, Santos, V, Casas, J, and García-Ochoa, F (2004) Use of flow cytometry for growth structured kinetic model development application to Candida bombicola growth. Enzyme Microb Technol 34: 399-406.

Akaike, H (1976) Canonical Correlation Analysis of Time Series and the Use of an Information Criterion. Raman, KM and Dimitri, GL. Elsevier 126: 27-96.

Amor, K, Breewuer, P, Verbaarschot, P, Rombouts, F, Akkermans, A, De Vos, W, and Abee, T (2002) Multiparametric flow cytometry and cell sorting for the assessment of viable, injured, and dead bifidobacterium cells during bile salt stress. Appl Environ Microbiol Nov: 5209-5216.

Berney, M, Weilenmann, H, and Egli, T (2006) Flow cytometry study of vital cellular functions in Escherichia coli during solar disinfection (SODIS). Curr Opin Microbiol 152: 1719-1729.

Blanco, A (2003) Microbiology in papermaking. Recent Res Dev Appl Microbio Biot 1: 87-134.

Blanco, A., Negro, C., Monte, C., Fuente, E., and Tijero, J. (2004) The challenges of sustainable papermaking. Environ Sci Tech 38(21): 414A420A.

Denis, JE, Gay, DM, and Welsch, RE (1981) Algorithm 573:NL2SOL- An Adaptative Nonlinear Least-squares Algorithm. ACM Trans Math Softw 7(3): 369-383.

Diaz, M, Herrero, M, García, LA, and Quirós, C (2010) Application of flow cytometry to industrial microbial bioprocesses. Biochem Eng J 48: 385-407. 
Foladori, P, Bruni, L, Tamburini, S, and Ziglio G (2010) Direct quantification of bacterial biomass in influent, effluent and activated sludge of wastewater treatment plants by using flow cytometry. Water Res $44: 3807-3818$.

Gautschi, W. (1997) Numerical Analysis: An introduction. Boston: Birkhäuser.

Gregori, G, Citterio, S, Ghiani, A, Labra, M, Sgorbati, S, Brown, S, and Denis, M (2001) Resolution of viable and memebrane compromised bacteria in freshwater ans marine waters based on analytical flow cytometry and nucleic acid double staining. Appl Environ Microbiol 67: 4662-4670.

Hammes, F, Berney, M, Wang, Y, Vital, M, Köster, O, and Egli T (2008) Flowcytometric total bacterial cells counts as a descriptive microbiological parameter for drinking water treatment processes. Water Res 42: 269-277.

Herrero, M, Quirós, C, García, LA, and Díaz M (2006) Use of flow cytometry to follow the physiological states of microorganisms in cider fermentation processes. Appl Environ Microbiol 72: 6725-6733.

Hewitt, C, and Nebe-Von-Caron, G (2004) The application of multi-parameter flow cytometry to monitor individual microbial cell physiological state. Adv Biochem Engin Biotecnol 89: 197-223.

Johnsrud, C (2000) Paper mill micro-organisms Inv Tec Papel. 497-506.

Joux, F, and Lebaron, P (2000) Use of fluorescent probes to assess physiological functions of bacteria at single-cell level. Microbes Infect 2(12): 1523-1535.

Knol, JJ, Linssen JPH, and Van Boekel, MAJS (2010) Unravelling the kinetics of the formation of acrylamide in the Maillard reaction of fructose and asparagine by multiresponse modelling. Food Chem 120: 1047-1057. 
Kolari, M, Nuutinen, J, Rainey, FA, and Salkinoja-Salonen, MS (2003) Colored moderately thermophilic bacteria in paper-machine biofilms. J Ind Microbiol Biotech 30(4): 225-238.

Labas, M, Zalazar, C, Brandi, R, and Cassano, A (2008) Reaction Kinetics of bacteria disinfection employing hydrogen peroxide. Biochem Engin J 38: 7887.

Lacroix, C, and Yildrim, S (2007) Fermentation technologies for the production of probiotics with high viability and functionality. Curr Opin Biotechnol 18: 176-183.

Lahtinen, T, Kosone, M, Tiirola, M, Vuento, M, Oker-Blom, C (2006) Diversity bacteria contaminating paper machines. J Ind Microbiol Biotechnol 33: 734740

Lisle, JT, Pyle, BH, and McFeters, GA (1999) The use of multiple indices of physiological activity to access viability in chlorine disinfected Escherichia coli O157:H7. Lett Appl Microbiol 29(1): 42-47.

Marks, BP (2008) Status of Microbial Modeling in Food Process Models. Compr Rev Food Sci Food Saf 7: 137-143.

Nebe-von-Caron, G, Stephens, P, Hewitt, C, Powell J, and Badley R (2000) Analysis of bacterial function by multi-color fluorescence flow cytometry and single cell sorting. J Microbiol Methods 42: 97-114.

Novo, DJ, Perlmutter, NG, Hunt, RH, and Shapiro, HM (2000) Multiparameter flow cytometric analysis of antibiotic effects on membrane potential, membrane permeability, and bacterial counts of Staphylococcus aureus and Micrococcus luteus. Antimicrob Agents Chemother 44 (4): 827-834. 
Oliver, JD (2005) The viable but non culturable state in bacteria. J Microbiol Febrero: 93-100.

Quiros, C, Herrero, M, García, L, and Díaz, M (2007) Application of flow cytometry to segregated kinetic modeling based on the physiological states of microorganisms. Appl Environ Microbiol June: 3993-4000.

Quiros, C, Herrero, M, García, L, and Díaz, M (2009) Quantitative approach to determine the contribution of viable-but-noncultivable subpopulations to malolactic fermentation processes. Appl Environ Microbiol May: 2977-2981.

Shapiro, HM (2003) Practical flow cytometry, fourth ed. John Wiley \& Sons, Inc., Hoboken, New Jersey.

Shi, L, Guenther, S, Hubschmann, T, Wick, LY, Harms, H, and Mueller, S (2007) Limits of propidium iodide as a cell viability indicator for environmental bacteria. Cytometry Part A 71(8): 592-598.

Torres, CE, Gibello, A, Nande, M, Martin, M., Blanco, A (2008) Fluorescent in situ hybridization and flow cytometry as tools to evaluate the treatments for the control of slime-forming enterobacteria in paper mills. Appl Microbiol Biotechnol 8: 889-897.

Verhoef, R, Schols, HA, Blanco, A, Siika-aho, M, Ratto, M, Buchert, J, Lenon, G, and Voragen, AGJ (2005) Sugar composition and FT-IR analysis of exopolysaccharides produced by microbial isolates from paper mill biofilm deposits. Biot Bioeng 91(1): 91-105.

Vives-Rego, J, Lebaron, P, Nebe-von Caron, G (2000) Current applications of flow cytometry in aquatic microbiology. Fems Microbiol Rev 24: 429-448. 
Xiaofeng, W, and Krull, U (2005) Synthesis and fluorescence studies of thiazole orange tethered onto oligonucleotide: development of a self-contained DNA biosensor on a fiber optic surface. Bioorg Med Chem Lett 15(6):i 1725-1729. 
Table 1.- Comparison between the proposed kinetic models for bacterial strain E-981024:statistical parameters.

\begin{tabular}{|llllll|}
\hline $\begin{array}{c}\text { Model number } \\
\text { equations }\end{array}$ & Parameters & Value \pm error & SQR & F $_{95}$ & AICc \\
\hline & $\mathrm{C}_{V_{\max }}$ & $5.33 \cdot 10^{-1} \pm 8.13 \cdot 10^{-3}$ & & & \\
& $\mathrm{C}_{\mathrm{Mmax}}$ & $1.85 \cdot 10^{-1} \pm 7.09 \cdot 10^{-3}$ & & & \\
Model 1 & $\mathrm{k}_{1}$ & $6.04 \cdot 10^{-1} \pm 1.81 \cdot 10^{-2}$ & & & \\
(eq. 3 to eq. 7) & $\mathrm{k}_{2}$ & $6.89 \cdot 10^{-1} \pm 3.81 \cdot 10^{-2}$ & & & \\
$\mathrm{t}_{\mathrm{v}}=0, \mathrm{t}_{\mathrm{m}}=0$ & $\mathrm{k}_{3}$ & $-9.97 \cdot 10^{-1} \pm 1.82 \cdot 10^{-1}$ & & & \\
& $\mathrm{k}_{4}$ & $-3.07 \pm 4.18 \cdot 10^{-1}$ & & & \\
& $\mathrm{C}_{V_{\max }}$ & $5.33 \cdot 10^{-1} \pm 3.83 \cdot 10^{-3}$ & & & \\
& $\mathrm{C}_{\mathrm{Mmax}}$ & $2.06 \cdot 10^{-1} \pm 3.83 \cdot 10^{-3}$ & & & \\
& $\mathrm{k}_{1}$ & $6.10 \cdot 10^{-1} \pm 7.42 \cdot 10^{-3}$ & & & \\
Model 2 & $\mathrm{k}_{2}$ & $4.56 \cdot 10^{-1} \pm 1.54 \cdot 10^{-2}$ & & & \\
(eq. 3 to eq. 7) & $\mathrm{k}_{3}$ & $9.93 \pm 5.44$ & & & \\
& $\mathrm{k}_{4}$ & $25.5 \pm 14.1$ & & & \\
& $\mathrm{t}_{\mathrm{v}}$ & $-7.96 \pm 1.53$ & & & \\
& $\mathrm{t}_{\mathrm{m}}$ & $-6.41 \pm 1.07$ & & & \\
\hline
\end{tabular}

Note: $\mathrm{C}_{\mathrm{V} \max }, \mathrm{C}_{\mathrm{Mmax}}\left(\mathrm{g} \mathrm{L}^{-1}\right) ; \mathrm{k}_{1}, \mathrm{k}_{2}\left(\mathrm{~g} \mathrm{~L}^{-1} \cdot \mathrm{min}^{-1}\right), \mathrm{k}_{1}, \mathrm{k}_{2}$ (dimensionless), $\mathrm{t}_{\mathrm{v}}, \mathrm{t}_{\mathrm{m}}(\min )$. 
Table 2.- Comparison between the proposed kinetic models for bacterial strain E-022115:statistical parameters.

\begin{tabular}{|c|c|c|c|c|c|}
\hline $\begin{array}{l}\text { Model number - } \\
\text { equations }\end{array}$ & Parameters & Value \pm error & SQR & $F_{95}$ & AICc \\
\hline \multirow{6}{*}{$\begin{array}{l}\text { Model } 1 \\
\text { (eq. } 3 \text { to eq. } 7 \text { ) } \\
t_{v}=0, t_{m}=0\end{array}$} & $\mathrm{C}_{V \max }$ & $4.58 \pm 1.42 \cdot 10^{-1}$ & \multirow{6}{*}{$3.98 \cdot 10^{-1}$} & \multirow{6}{*}{748} & \multirow{6}{*}{-2.86} \\
\hline & $\mathrm{C}_{\mathrm{Mmax}}$ & $1.62 \pm 3.48 \cdot 10^{-1}$ & & & \\
\hline & $\mathrm{k}_{1}$ & $6.42 \cdot 10^{-1} \pm 1.34 \cdot 10^{-2}$ & & & \\
\hline & $\mathrm{k}_{2}$ & $3.35 \cdot 10^{-1} \pm 4.68 \cdot 10^{-2}$ & & & \\
\hline & $\mathrm{k}_{3}$ & $1.40 \cdot 10^{-1} \pm 3.27 \cdot 10^{-2}$ & & & \\
\hline & $\mathrm{k}_{4}$ & $4.50 \cdot 10^{-1} \pm 8.35 \cdot 10^{-2}$ & & & \\
\hline \multirow{8}{*}{$\begin{array}{l}\text { Model } 2 \\
\text { (eq. } 3 \text { to eq. } 7 \text { ) }\end{array}$} & $\mathrm{C}_{V \max }$ & $4.62 \pm 7.21 \cdot 10^{-2}$ & \multirow{8}{*}{$9.58 \cdot 10^{-2}$} & \multirow{8}{*}{2312} & \multirow{8}{*}{-4.06} \\
\hline & $\mathrm{C}_{\mathrm{Mmax}}$ & $1.29 \pm 8.59 \cdot 10^{-2}$ & & & \\
\hline & $\mathrm{k}_{1}$ & $6.40 \cdot 10^{-1} \pm 6.65 \cdot 10^{-3}$ & & & \\
\hline & $\mathrm{k}_{2}$ & $4.14 \cdot 10^{-1} \pm 3.03 \cdot 10^{-2}$ & & & \\
\hline & $\mathrm{k}_{3}$ & $5.19 \cdot 10^{-1} \pm 1.70 \cdot 10^{-1}$ & & & \\
\hline & $\mathrm{k}_{4}$ & $1.94 \pm 6.49 \cdot 10^{-1}$ & & & \\
\hline & $t_{v}$ & $-3.77 \pm 1.61$ & & & \\
\hline & $t_{m}$ & $-5.54 \pm 1.01$ & & & \\
\hline
\end{tabular}

Note: $\mathrm{C}_{\mathrm{V}_{\max }}, \mathrm{C}_{\mathrm{Mmax}}\left(\mathrm{g} \mathrm{L}^{-1}\right) ; \mathrm{k}_{1}, \mathrm{k}_{2}\left(\mathrm{~g} \mathrm{~L}^{-1} \cdot \mathrm{min}^{-1}\right), \mathrm{k}_{1}, \mathrm{k}_{2}$ (dimensionless), $\mathrm{t}_{\mathrm{v}}, \mathrm{t}_{\mathrm{m}}(\min )$. 
Figure 1.- Dot plots obtained for each sample analysed by FC. Region R1 correspond to dead cells, R2 region represent damage cells, R3 correspond to viable cells, and Region R4 correspond to beads events.
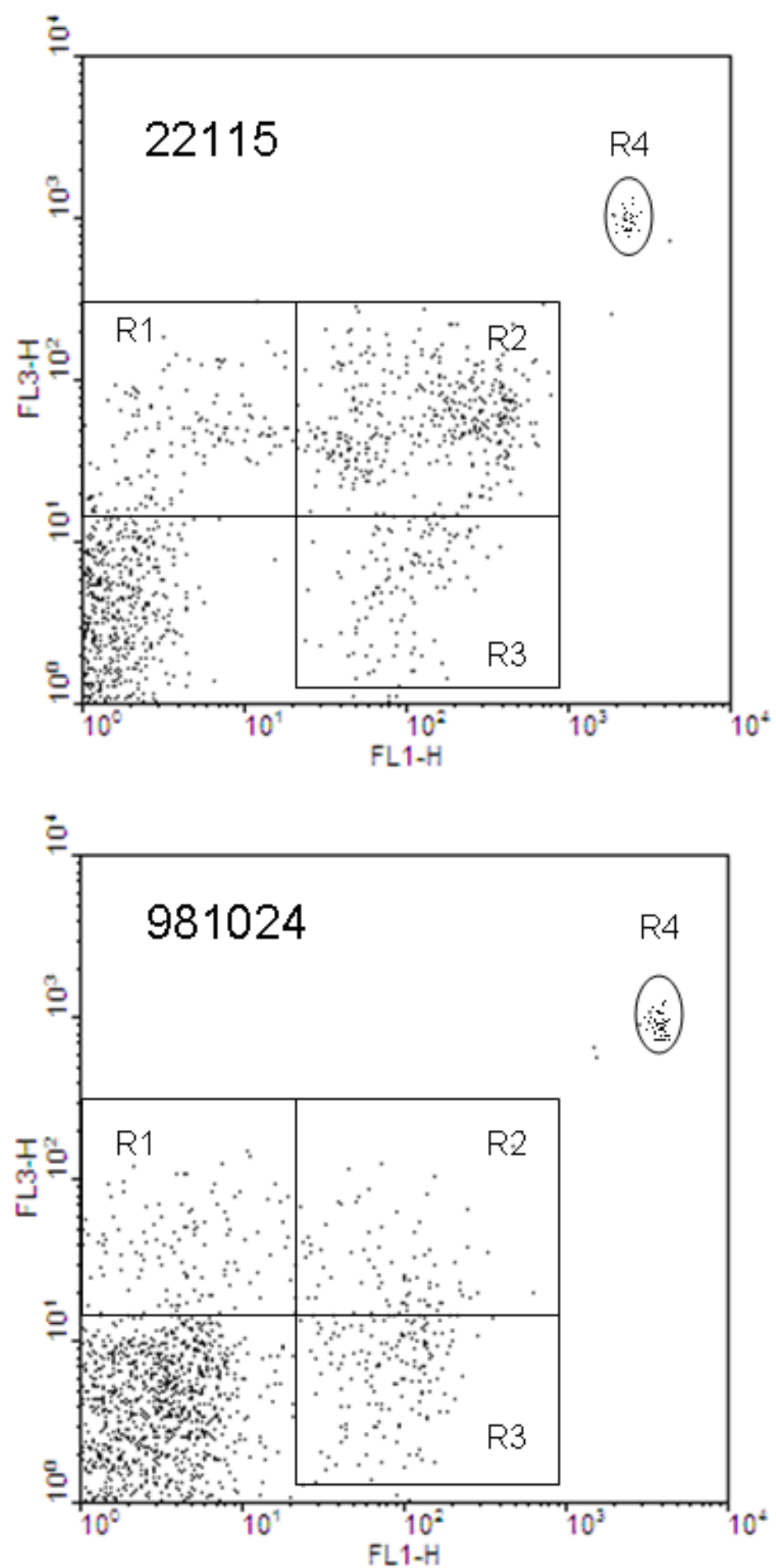
Figure 2.- Concentration of total biomass $\left(\mathrm{g} . \mathrm{L}^{-1}\right)$. Comparison between $\mathrm{FC}(\bullet)$ and $\mathrm{OD}(\circ)$ techniques.
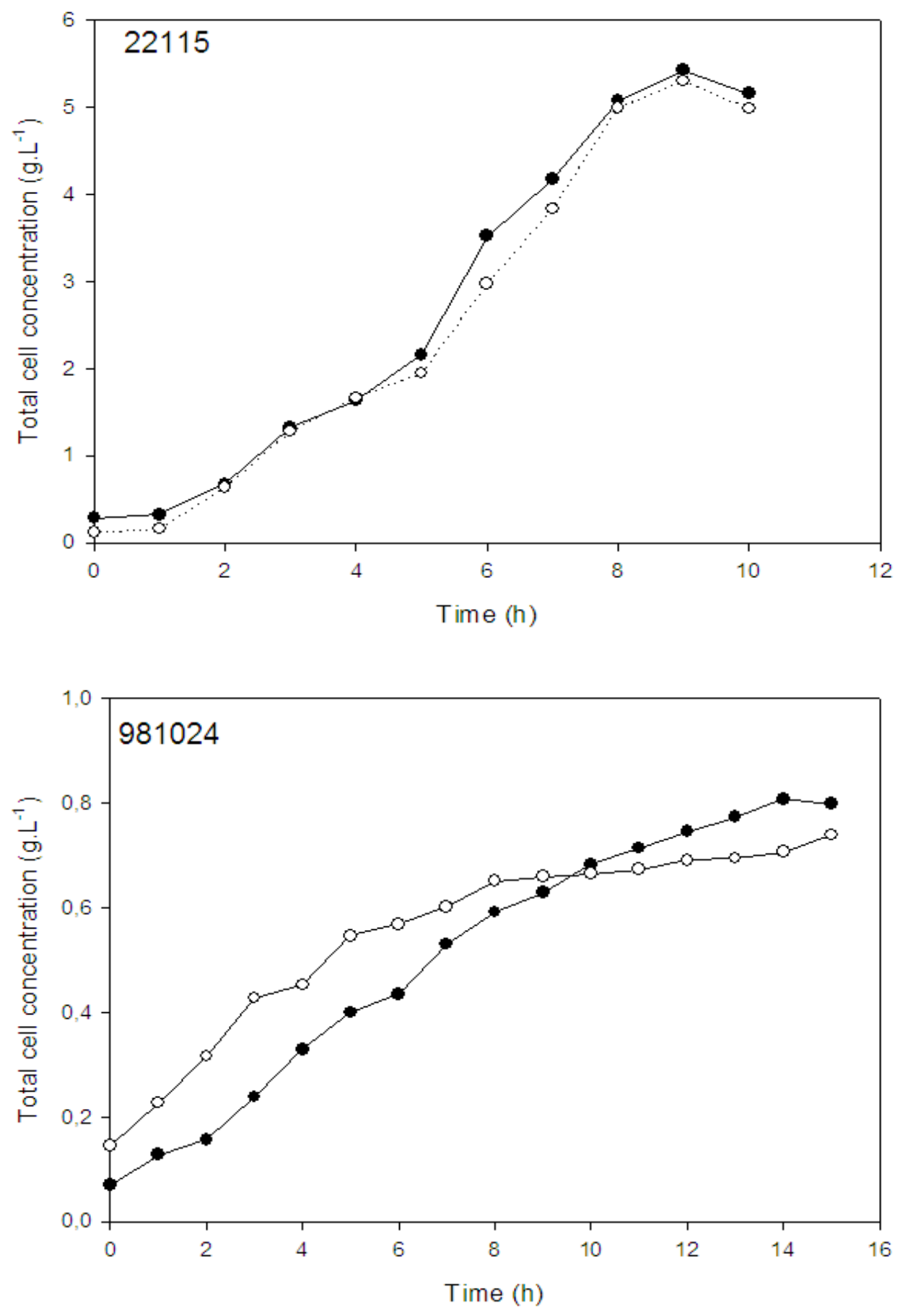
Figure 3.- Results obtained by flow cytometry for both strains. Viable cells populations $(\mathbf{\Lambda})$, damage cells $(\mathbf{\square})$ and dead cells $(\bullet)$.
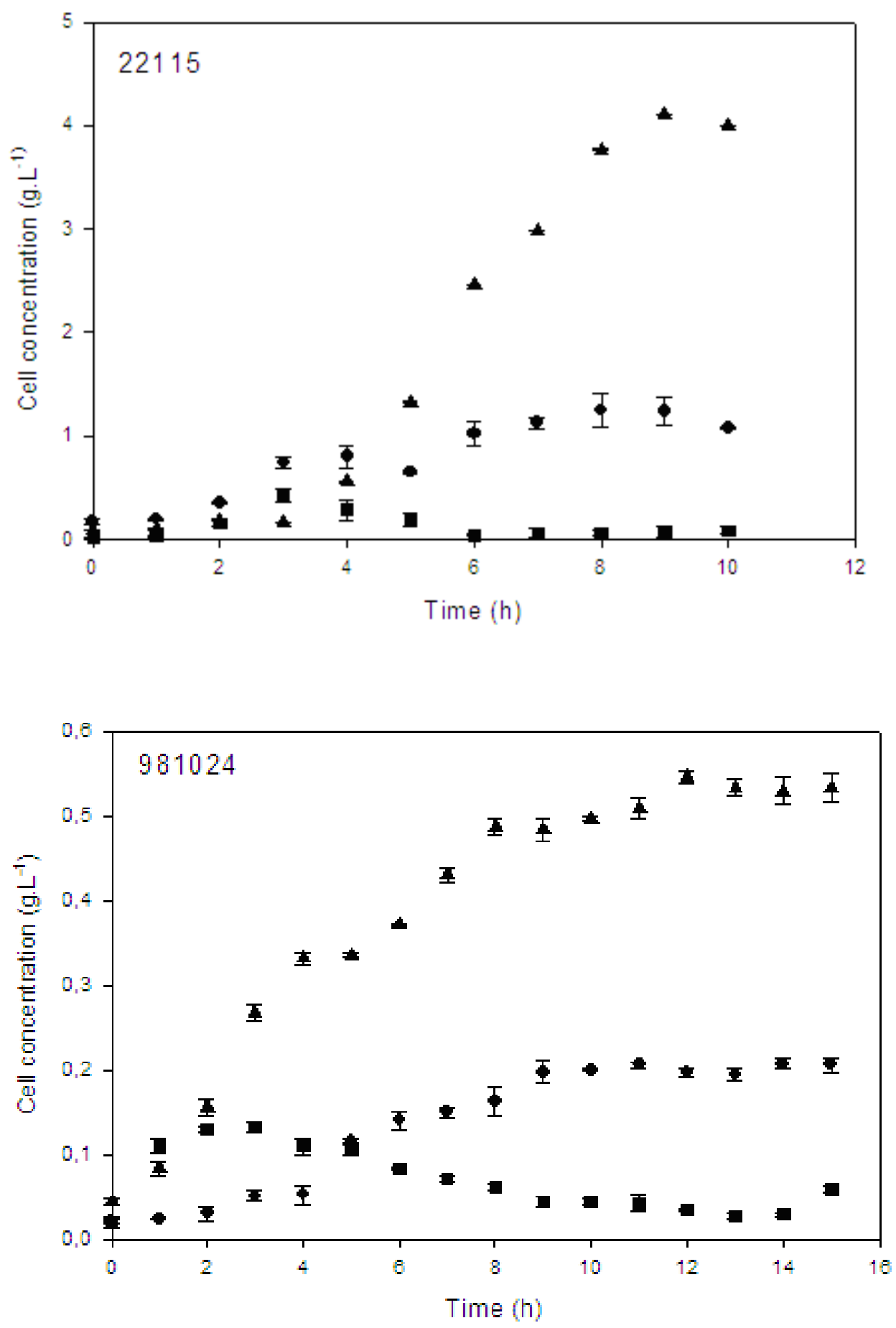
Figure 4.- Fitting of Model 1 to viable, damaged and dead cells of strains E-981024 and E-022115. Viable cells populations ( $\mathbf{\Delta})$, damage cells ( $\mathbf{(})$ dead cells $(\bullet)$,and $(-)$ model line.
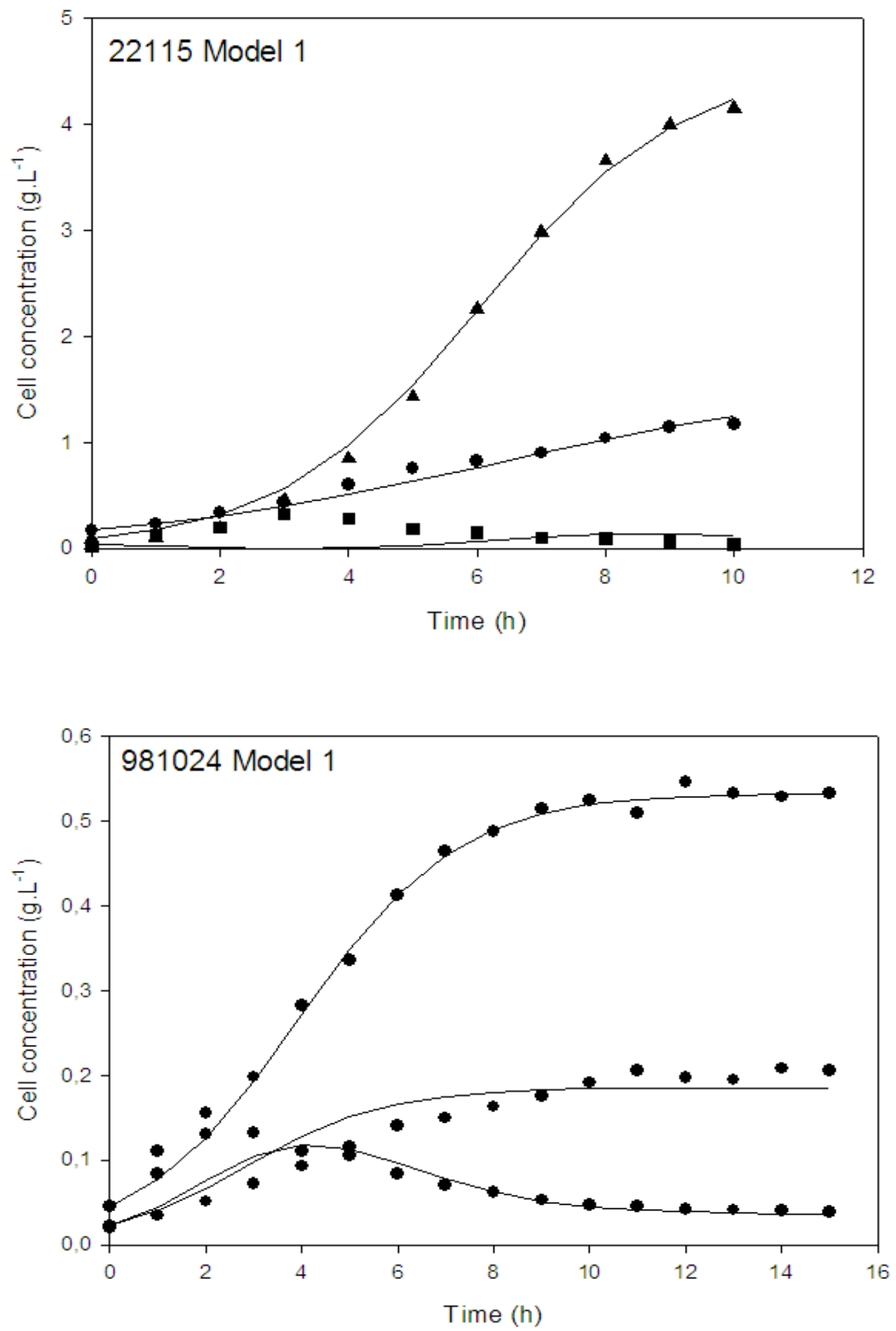
Figure 5.- Fitting of Model 2 to viable, damaged and dead cells of strains E-981064 and E-022115. Viable cells populations ( $\mathbf{\Delta})$, damage cells ( $\mathbf{(})$ dead cells $(\bullet)$ and $(-)$ model line.
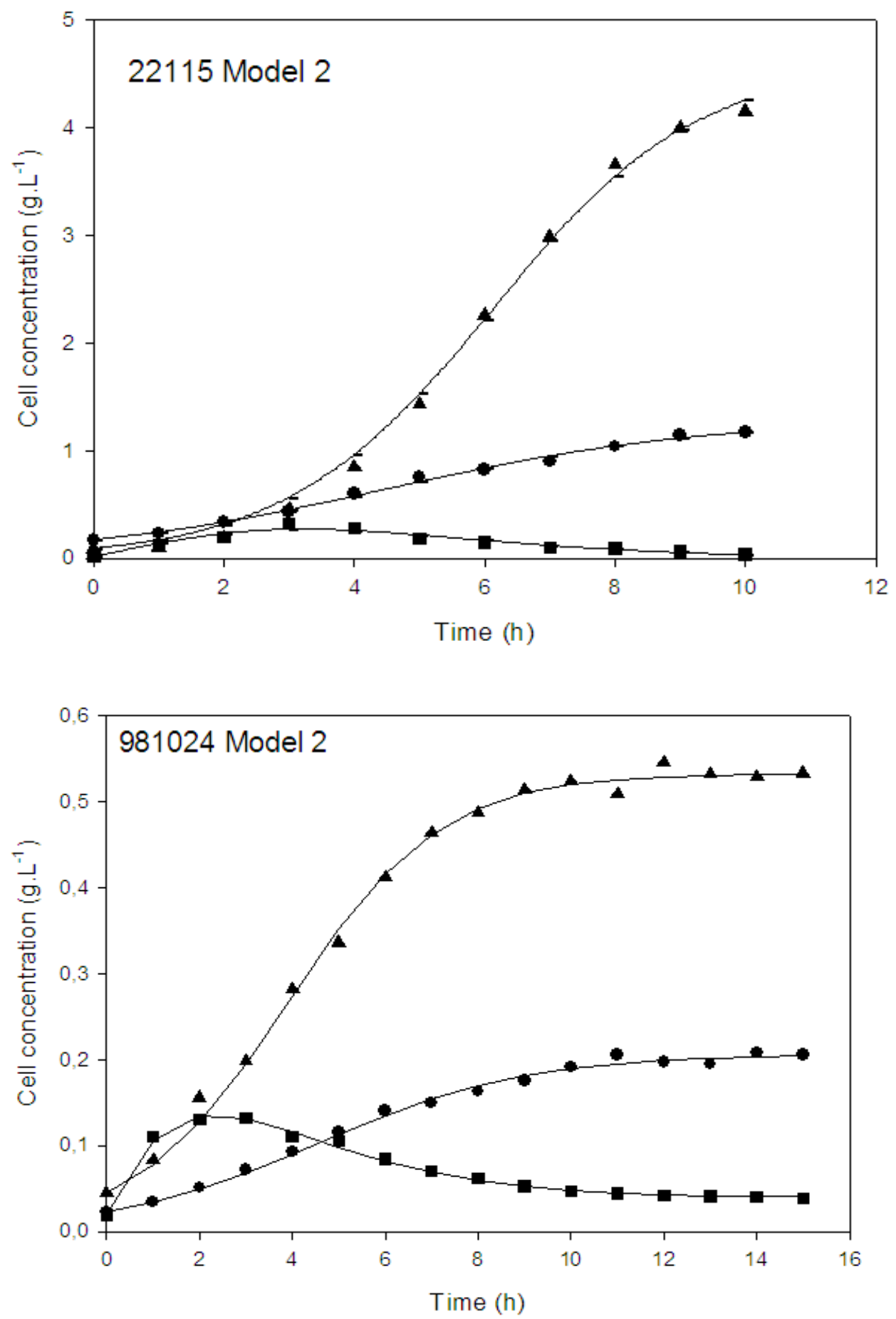